\title{
BIOMETRIA DE FRUTOS E SEMENTES E GERMINAÇÃO DE CURUPIXÁ (Micropholis cf. venulosa MART. \& EICHLER - Sapotaceae)
}

\author{
Eniel David CRUZ ${ }^{1}$ \& José Edmar Urano de CARVALHO ${ }^{1}$
}

\begin{abstract}
RESUMO - Micropholis cf. venulosa Mart. \& Eichler, conhecida como curupixá, é uma espécie arbórea que vem sendo explorada pelas industrias madeireiras do Estado do Pará. O objetivo do trabalho foi estudar as características biométricas de frutos e sementes de curupixá e avaliar o efeito do dessecamento na germinação das sementes. Determinou-se o comprimento e o diâmetro dos frutos, o número de sementes por frutos, a porcentagem de sementes danificadas por insetos e o comprimento, a largura e a espessura das sementes. No controle (sementes frescas) e nas sementes submetidas ao dessecamento em sílica gel durante 72 e 96 horas, foram quantificadas as porcentagens de germinação, de plântulas anormais, de sementes mortas, tempo médio de germinação e o número de dias para iniciar a germinação. A semeadura foi realizada em substrato de areia e serragem curtida (1:1), em quatro repetições de 50 sementes. $O$ fruto de curupixá é uma baga oblonga cujo comprimento e diâmetro dos frutos variaram de 32,5 a 72,9 mm e de 29,1 a $58,0 \mathrm{~mm}$, respectivamente. O número de sementes por fruto variou de um a três, com $53,3 \%$ delas danificadas por insetos. O comprimento, a largura e a espessura das sementes variaram de 15,5 a $41,4 \mathrm{~mm}$, de 8,0 a $18,7 \mathrm{~mm}$ e de 4,7 a $12,6 \mathrm{~mm}$, respectivamente. Nas sementes frescas observou-se que a germinação foi lenta e com acentuada desuniformidade, iniciando 24 dias após a semeadura e atingindo a germinação final de 55\% aos 96 dias após a semeadura. Registrou-se reduções significativas na germinação das sementes submetidas ao dessecamento e, aumento no número de dias para iniciar a germinação e na porcentagem de sementes mortas. A redução do grau de umidade de $42,6 \%$ para $28,9 \%$ reduziu a germinação de $55 \%$ para $24,7 \%$ e aumentou a porcentagem de sementes mortas de $40,5 \%$ para $70 \%$, indicando que sementes dessa espécie apresentam sensibilidade ao dessecamento.
\end{abstract}

Palavras-chave: Dessecamento, semente recalcitrante, tempo médio de germinação

\section{Fruit and seed biometry and germination of Micropholis cf. venulosa Mart. \& Eichler (Sapotaceae)}

\begin{abstract}
Micropholis cf. venulosa Mart. \& Eichler, knwon as curupixá, is a tree largely used in forest exploitation in the State of Pará. The objective was to study the biometrics features of fruit and seeds and the effect of desiccation on seed germination. It was measured the length and diameter of fruits, number of seeds per fruits, percentage of seeds damaged by insects, length, width and thickness of seeds. For control (fresh seeds) and desiccated seeds, the percentage of germination, of abnormal seedlings, of dead seeds, mean time germination and number of days to first germination were also measured. Seeds were desiccated by storage on silica gel for 72 and 96 hours. Sowing was carried out on a substrate containing sand and sawdust (1:1), in four replicates of 50 seeds. Length and diameter of the fruits ranged from 32.5 to 72.9 $\mathrm{mm}$ and 29.1 to $58.0 \mathrm{~mm}$, respectively. Fruits had one to three seeds, and $53.3 \%$ of them were damaged by insects. The $M$. cf. venulosa fruit is a bacca with length, width and thickness of seeds ranged from 15.5 to $41.1 \mathrm{~mm}, 8.0$ to $18.7 \mathrm{~mm}$ and 4.7 to $12.6 \mathrm{~mm}$, respectively. For control seeds germination was slow and non-uniform, and started 24 days after sowing. Total germination (55\%) was recorded 96 days after sowing. It was observed a significant reduction on

${ }^{1}$ Pesquisadores da Embrapa Amazônia Oriental, Caixa Postal 48, CEP 66017-970, Belém, PA, Brasil. E-mail: eniel@cpatu.embrapa.br.
\end{abstract}


germination of desiccated seed and an increase on the number days to first germination and on the percentage the dead seeds. Moisture reduction in seeds from $42.6 \%$ to $28.9 \%$ reduced germination to $24.7 \%$ and increased the percentage of dead seeds to $70 \%$, indicating that seeds of this species are sensitive to desiccation.

Key-words: Desiccation, mean time germination, recalcitrant seed,

\section{INTRODUÇÃO}

O curupixá, Micropholis cf. venulosa Mart. \& Eichler, conhecida como abioranamangabinha, abiu-guajará, gogó-de-guariba, guajará, grumixá, grumixava e rosadinho (Souza et al., 1997), é uma espécie de grande porte, que ocorre no Brasil, nos Estados do Amazonas, Acre, Pará e Rondônia, além da Colômbia, Peru, Venezuela e Guianas, podendo atingir altura de $70 \mathrm{~m}$ e diâmetro de $150 \mathrm{~cm}$ (Roosmalen \& Garcia, 2000). A madeira dessa espécie apresenta densidade de $790 \mathrm{~kg} / \mathrm{m}^{3}$, sendo resistente à podridão-branca e muito resistente à podridão-parda, porém, suscetível ao ataque de cupins da madeira. De acordo com Souza et al. (1997), sua madeira é utilizada na construção civil, móveis, brinquedos, utensílios domésticos e produção de chapas.

Na região oeste do Pará, a frutificação de Micropholis spp. ocorre nos meses de janeiro a maio e a viabilidade da semente é inferior a um mês (Knowles \& Parrotta, 1995). Quanto a dispersão das sementes Roosmalen \& Garcia (2000) observaram que pássaros e macacos são os responsáveis.

O curupixá vem sendo explorado extrativamente pelo setor madeireiro do Estado do Pará, tendo importante papel na pauta de exportações do Estado, com $244.000 \mathrm{~m}^{3}$ de madeira exportada, no período de 1990 a 1997 (Aimex, 1998).

Nas espécies arbóreas tropicais existe grande variabilidade com relação ao tamanho dos frutos, número de sementes nos frutos e tamanho das sementes, fatos comprovados por Cruz et al. (2001a e 2001b) em Parkia nitida Miquel e Hymenaea intermedia Ducke, respectivamente. Entretanto, poucos são os trabalhos que objetivam a caracterização de frutos e sementes dessas espécies visando ampliar o conhecimento sobre as mesmas (Edwards, 2000). Para Vázquez-Yanes \& Aréchiga (1996), o aumento no conhecimento sobre as sementes das espécies tropicais possibilitará maior uso de espécies nativas em plantios e reflorestamentos.

A redução do grau de umidade das sementes pode reduzir significativamente a germinação (Carvalho \& Müller, 1998). As sementes que apresentam sensibilidade ao dessecamento podem ser classificadas com intermediárias (Carvalho \& Nascimento, 2000; Varghese \& Naithani, 2000) ou recalcitrante (Carvalho \& Müller, 1998). Na família Sapotaceae a existência de espécies arbóreas com sementes recalcitrante foram reportadas por Carvalho et al. (2001) e Vásquez-Yanes et al. (2000).

O objetivo do presente estudo foi determinar as características biométricas de frutos e sementes e avaliar a sensibilidade de sementes de curupixá ao dessecamento. As hipóteses a serem testadas são que frutos e sementes de curupixá apresentam ampla variabilidade com relação as características biométricas e, as sementes dessa espécie apresentam sensibilidade ao dessecamento e, conseqüentemente, comportamento recalcitrante no armazenamento.

\section{MATERIAL E MÉTODOS}

\section{Local de coleta e de avaliação}

Os frutos maduros, originários de seis árvores, foram coletados no solo após o desprendimento natural das plantas, em floresta nativa, no município de Paragominas, Estado do Pará (0240'56”'S e 46\%49'59'O). Foram transportados para a Embrapa Amazônia Oriental, em Belém, Pará, onde permaneceram por cinco dias em bandejas plásticas, em condições ambientais locais (luz natural, temperatura média de $27,5^{\circ} \mathrm{C}$ e umidade relativa do ar média de $84 \%$ ), até o início das avaliações. 


\section{Biometria de frutos e sementes}

Efetuou-se a classificação do fruto de acordo Spjut (1994). Determinou-se comprimento e o diâmetro dos frutos (Fig. 1), com paquímetro digital, e o número de sementes por frutos, em uma amostra de 647 frutos. A porcentagem de sementes boas e de sementes danificadas por insetos foi determinada em 735 sementes. Foram consideradas sementes danificadas por insetos toda semente que apresentasse orifício indicando a presença de larva ou adulto (Brasil, 1992). Em uma amostra de 376 sementes foram tomadas medidas do comprimento, da largura e da espessura (Fig. 1). Considerou-se como comprimento a porção compreendida entre a porção basal e a apical da semente. A largura e a espessura foram medidas na parte intermediária da semente. A massa de 100 sementes foi obtida por meio do peso de oito repetições com a essa mesma quantidade de sementes.

\section{Germinação de sementes}

O teste de tetrazólio, aplicado visando a verificação da vitalidade to tecido vegetal, foi conduzido com quatro repetições de 25 sementes. Efetuou-se inicialmente a remoção do tegumento sendo em seguida imersas por 13 horas, em solução de tetrazólio, na concentração de $0,5 \%$. Após esse período as sementes foram retiradas da solução e lavadas em água corrente, determinando-se então a percentagem de sementes viáveis. Foram consideradas viáveis as sementes que apresentaram coloração rósea uniforme em toda a sua extensão, assim como, aquelas que apresentavam pequenas áreas não coloridas nos cotilédones. A determinação do grau de umidade foi realizada em quatro repetições de dez sementes, pelo método da estufa a $105 \pm 3^{\circ} \mathrm{C}$, durante 24 horas, conforme Brasil (1992).

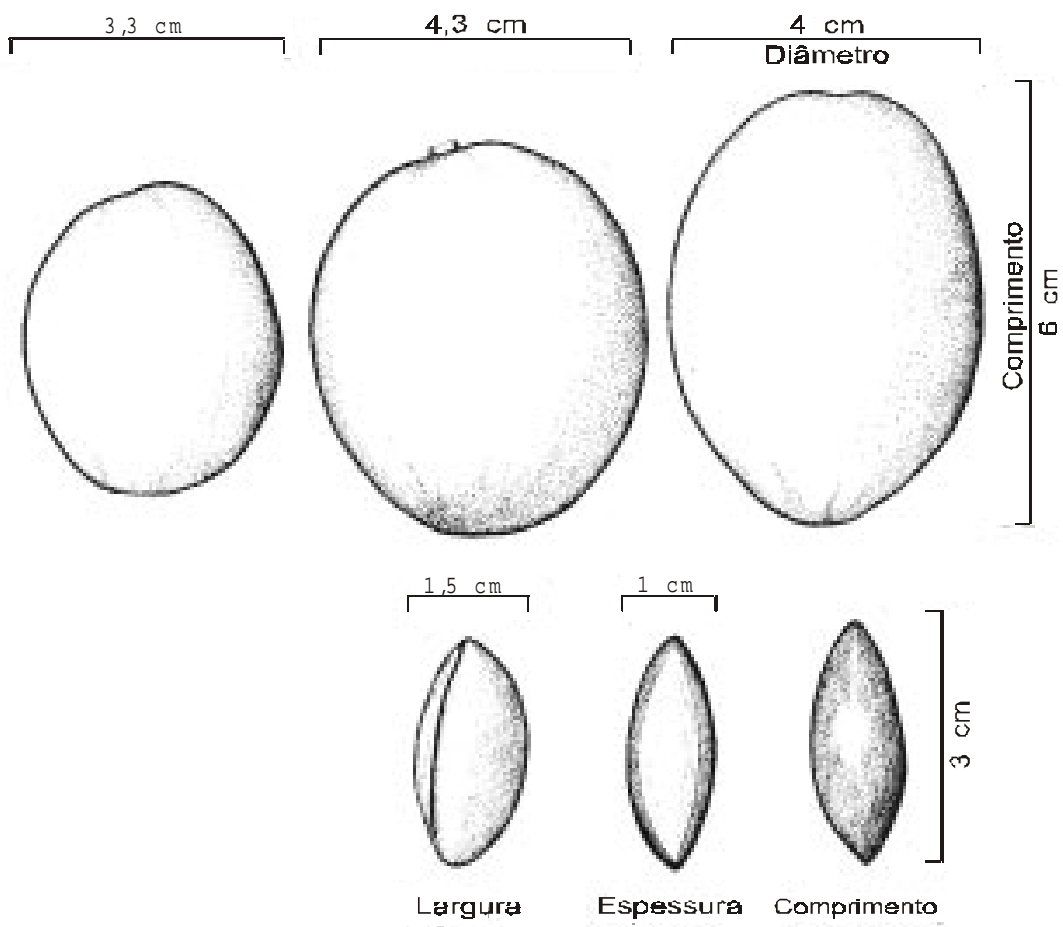

Figura 1 - Frutos e sementes de Micropholis cf. venulosa. 
Para avaliação da germinação, as sementes foram divididas em três lotes, sendo um lote semeado logo após a extração (sementes frescas), e os outros após permanecerem 72 e 96 horas em dissecadores contendo sílica gel, na proporção de 250 sementes para $1 \mathrm{~kg}$ de sílica gel (sementes dessecadas). Os recipientes com sílica gel permaneceram em local com temperatura e umidade relativa do ar ambiente de Belém (temperatura média de $27,5^{\circ} \mathrm{C}$ e umidade relativa do ar média de $84 \%$ ). As sementes foram semeadas sobre substrato constituído de areia e serragem curtida, previamente esterilizado em água fervente durante duas horas, na proporção volumétrica de $1: 1$. Após a semeadura as sementes foram cobertas com uma camada de aproximadamente $1,0 \mathrm{~cm}$ de espessura do mesmo substrato. Os substratos foram mantidos em condições ambientais locais e, irrigados a cada dois dias. Diariamente, foi quantificada a germinação e calculado o tempo médio de germinação (TMG) de acordo com Edmond \& Drapala (1965), através da equação

$$
\mathrm{TMG}=\frac{G_{1} T_{1}+G_{2} T_{2}+\ldots+G_{n} T_{n}}{G_{1}+G_{2}+\ldots+G_{n}}
$$

onde, Tm é o tempo médio necessário para atingir a germinação máxima; $\mathrm{G}_{1}, \mathrm{G}_{2}$ e $\mathrm{G}_{\mathrm{n}}$ é o número de sementes germinadas nos tempos $\mathrm{T}_{1}, \mathrm{~T}_{2}$ e $\mathrm{T}_{\mathrm{n}}$, respectivamente.

Considerou-se germinadas as sementes que apresentaram o primeiro par de folhas definitivas abertas, cujas plântulas foram consideradas normais, ou seja, com todas as estruturas essenciais bem desenvolvidas, completas, proporcionais e sadias. Foram determinados também os dias para início da germinação, ou seja, o número de dias decorridos da semeadura até o início da germinação, e as percentagens de plântulas anormais e de sementes mortas, conforme recomendação de Brasil (1992). Determinou-se também o tipo de germinação e o tipo de plântula conforme classificação de Duke \& Polhill (1981).

\section{Delineamento experimental e análise estatística}

Os testes de germinação foram conduzidos em delineamento inteiramente casualizado com três tratamentos (graus de umidade das sementes) e quatro repetições de 50 sementes. Os dados de biometria de frutos e sementes foram analisados através da distribuição de freqüência, sendo os intervalos de classe estimados de acordo com Beiguelman (1991) e Caballero (1985). Os dados referentes as variáveis germinação, tempo médio de germinação, dias para início da germinação e as percentagens de plântulas anormais e de sementes mortas, foram submetidos ao teste de Bartlett para verificação da homogeneidade das variâncias (Zar, 1996), o qual demonstrou ser necessário realizar a transformação da porcentagem de germinação e de dias para início da germinação, sendo utilizado $\sqrt{x / 100}$ e $\log (\mathrm{x}+1)$, respectivamente. Efetuou-se análise de variância e o teste de Tukey a 5\% para comparação das médias para todas as variáveis, exceto para a porcentagem de germinação que foi efetuada análise de regressão através do software Statistica (Statsoft, 1998). A tabela e os gráficos das regressões foram construídos com dados originais.

\section{RESULTADOS E DISCUSSÃO}

\section{Biometria de frutos e sementes}

O fruto de curupixá é uma baga oblonga, com epicarpo de cor amarela, quando completamente maduro, fato também comprovado por Roosmalen \& Garcia (2000). O comprimento variou de 32,5 a 72,9 mm (Fig. 2A) e o diâmetro de 29,1 a 58,0 mm (Fig. 2B). Predominaram frutos cujos comprimentos e diâmetros variaram de 46,0 a 54,9 mm e de 34,9 a 40,6 mm, respectivamente.

O número de sementes por fruto variou de um a três, sendo que $88,4 \%, 9,6 \%$ e $2,0 \%$ dos frutos apresentaram uma, duas e três sementes, respectivamente. Aproximadamente $53,3 \%$ das sementes, por ocasião da dispersão, apresentavam sintomas de ataque por insetos, sendo que em muitas delas foram encontradas larvas de inseto não identificadas. 

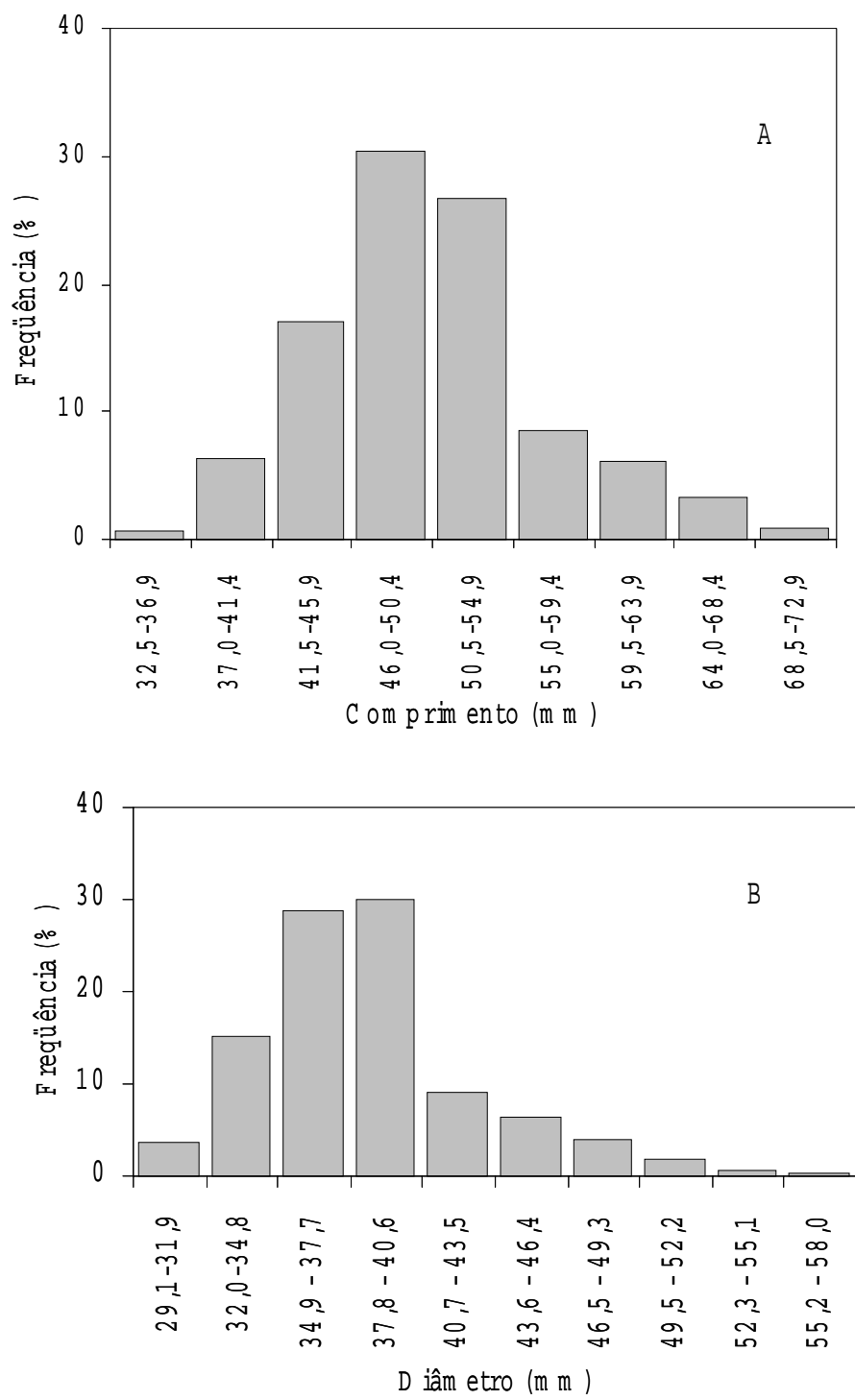

Figura 2 - Freqüências de comprimento (A) e diâmetro (B) de frutos de Micropholis cf. venulosa.

As sementes de curupixá são oblongas, com tegumento liso e de coloração tendendo para o preto, em quase toda a superfície, com exceção da face onde encontra-se a micrópila e o hilo, que é de coloração creme e cuja superfície é rugosa. A exemplo do observado para os frutos, as sementes de curupixá apresentaram grandes variações em suas dimensões com comprimento, largura e espessura variando de 15,5 a $41,4 \mathrm{~mm}$; 8,0 a $18,7 \mathrm{~mm}$ e 4,7 a $12,6 \mathrm{~mm}$ (Figs. $3 \mathrm{~A}, \mathrm{~B}$ e $\mathrm{C}$, respectivamente), sendo que a maioria das sementes apresentou comprimento, largura e espessura variando de 28,5 a 33,6 $\mathrm{mm} ; 12,8$ a $15,1 \mathrm{~mm}$ e 8,7 a $10,6 \mathrm{~mm}$, respectivamente. Em média, a massa de 100 sementes foi de $178,8 \pm 7,0 \mathrm{~g}$, com $42,6 \%$ de umidade. 

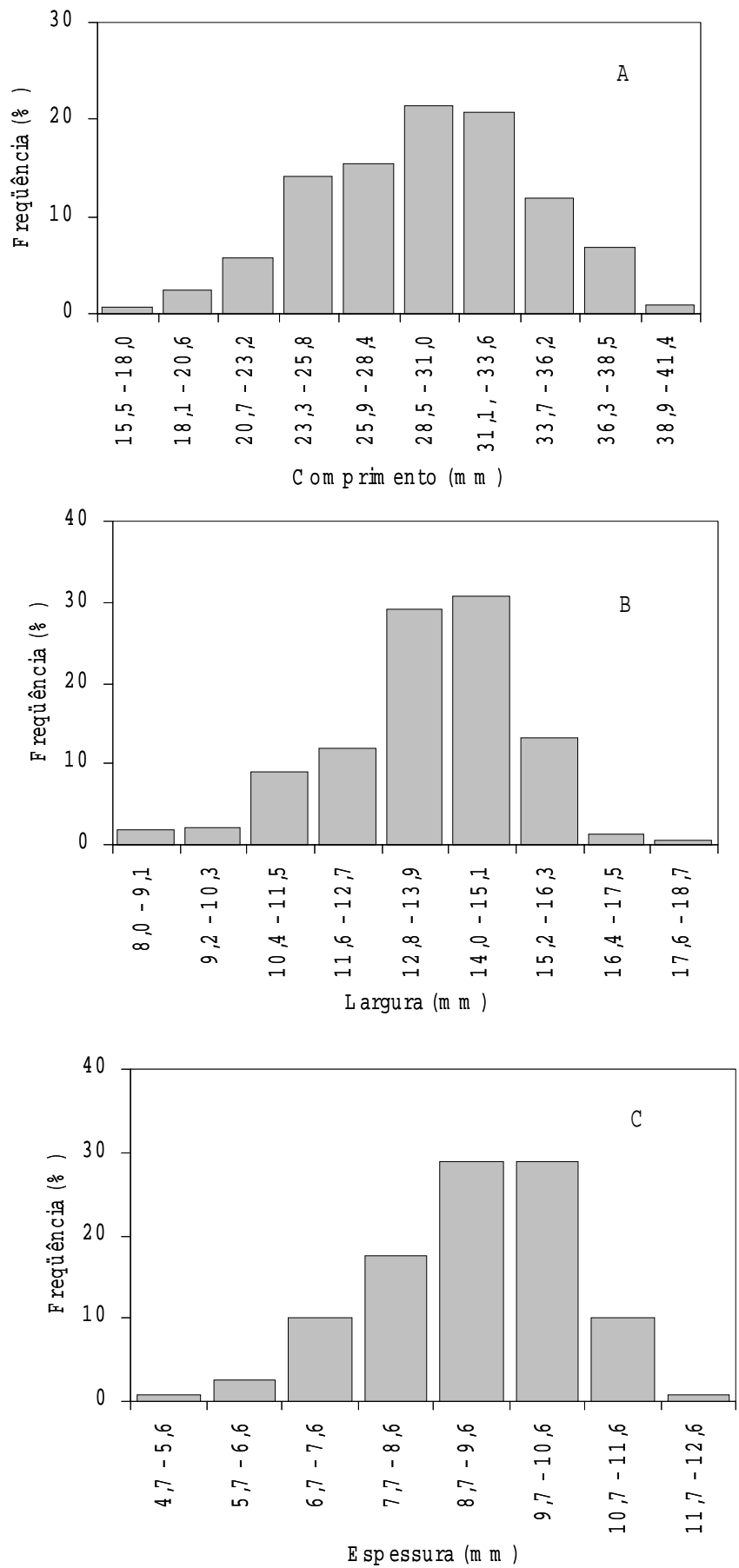

Figura 3 - Freqüências de comprimento (A), largura (B) e espessura (C) de sementes de Micropholis cf. venulosa. 


\section{Germinação das sementes}

Para as sementes recém extraídas dos frutos a porcentagem de sementes viáveis, determinada através do teste de tetrazólio, foi de $56 \%$, valor este semelhante ao observado para a porcentagem de germinação, 55\%. Por outro lado, quando as sementes foram submetidas à secagem parcial houve um decréscimo acentuado na porcentagem de germinação (Figs. 4A, B e C), que atingiu patamar de até $24,7 \%$, mostrando que sementes de curupixá apresentam sensibilidade à redução no grau de umidade, enquadrando-se, portanto, no grupo de sementes que apresentam comportamento recalcitrante no armazenamento. A ocorrência de sementes recalcitrantes é freqüente em espécies arbóreas tropicais (Neves, 1994) e, normalmente, sementes que pertencem a esse grupo são de tamanho grande e apresentam elevado grau de umidade por ocasião da dispersão (Chin, 1988), características estas também apresentadas pelas sementes de curupixá.

As sementes de curupixá apresentam germinação epigeal e as plântulas são do tipo fanerocotiledonares, semelhante ao observado por Carvalho et al. (1998) em Pouteria caimito (Ruiz et. Pavon) Radlk. O processo germinativo foi relativamente lento e desuniforme, iniciando-se, em sementes não submetidas à secagem, 24 dias após a semeadura (Fig. 4A). Villachica et al. (1996), também observaram que em $P$. macrophylla (Lam) Eyma, a germinação das sementes iniciou no $24^{\circ}$ e Carvalho et al. (1998) observaram que em $P$. caimito o início da germinação ocorreu a partir do $22^{\circ}$ dia após a semeadura. Para as sementes não submetidas ao dessecamento observou-se incrementos maiores na germinação até o $40^{\circ}$ dia (Fig. 4A). Entretanto para as sementes submetidas ao dessecamento os incrementos foram até o $64^{\circ}$ dia (Figs. 4B e C).

A baixa porcentagem de germinação, mesmo para as sementes não submetidas à secagem, pode ser considerada baixa, quando comparada com a observada em outras sapotáceas como P. macrophylla e P. caimito, cujas sementes apresentaram, normalmente, germinação variando entre $80 \%$ e $90 \%$, quando são semeadas logo após a extração dos frutos (Villachica et al., 1996; Carvalho et al., 1998). Provavelmente, tal fato tenha ocorrido em decorrência de que os frutos foram coletados no solo. Assim sendo, é possível que em alguns frutos as sementes já tivessem iniciado o processo de deterioração. Outro fato que pode comprometer a germinação de sementes recalcitrantes é o grau de umidade, visto que, o teor de água por ocasião da dispersão, pode não ser suficiente para promover a germinação, embora as sementes recalcitrantes apresentem alto grau de umidade por ocasião da dispersão (Baskin \& Baskin, 1998).

A redução no grau de umidade das sementes acarretou aumento no número de dias para iniciar a germinação, no tempo médio de germinação e nas percentagens de sementes mortas. Porém não alterou a percentagem de plântulas anormais (Tab. 1). A redução da germinação em sementes recalcitrantes devido a redução do grau de umidade tem sido reportada por vários autores (Carvalho \& Müller, 1998; Carvalho \& Nascimento, 2000; Corbineau \& Côme, 1988; Cunha et. al., 1995; Dayal \& Kaveriappa, 2000; Tompsett, 1985; Varghese \& Naithani, 2000). Para o tempo médio de germinação a redução do grau de umidade causou aumento de oito e doze dias para as sementes com umidade de $32,5 \%$ e $28,9 \%$, respectivamente, mostrando que com a redução do grau de umidade as sementes requereram mais tempo para a germinação. Carvalho \& Müller (1998) também observaram que em sementes de Bactris gasipaes Kunth, quando submetidas ao dessecamento, houve um aumento no número de dias para iniciar a germinação, ou seja as sementes retardaram o início da germinação. Os valores obtidos para o tempo médio de germinação de 33,2 e 41,4 dias para sementes frescas e sementes dessecadas por 72 horas, respectivamente, foram semelhantes aos registrados por Carvalho et al. (1998) em P. caimito. 

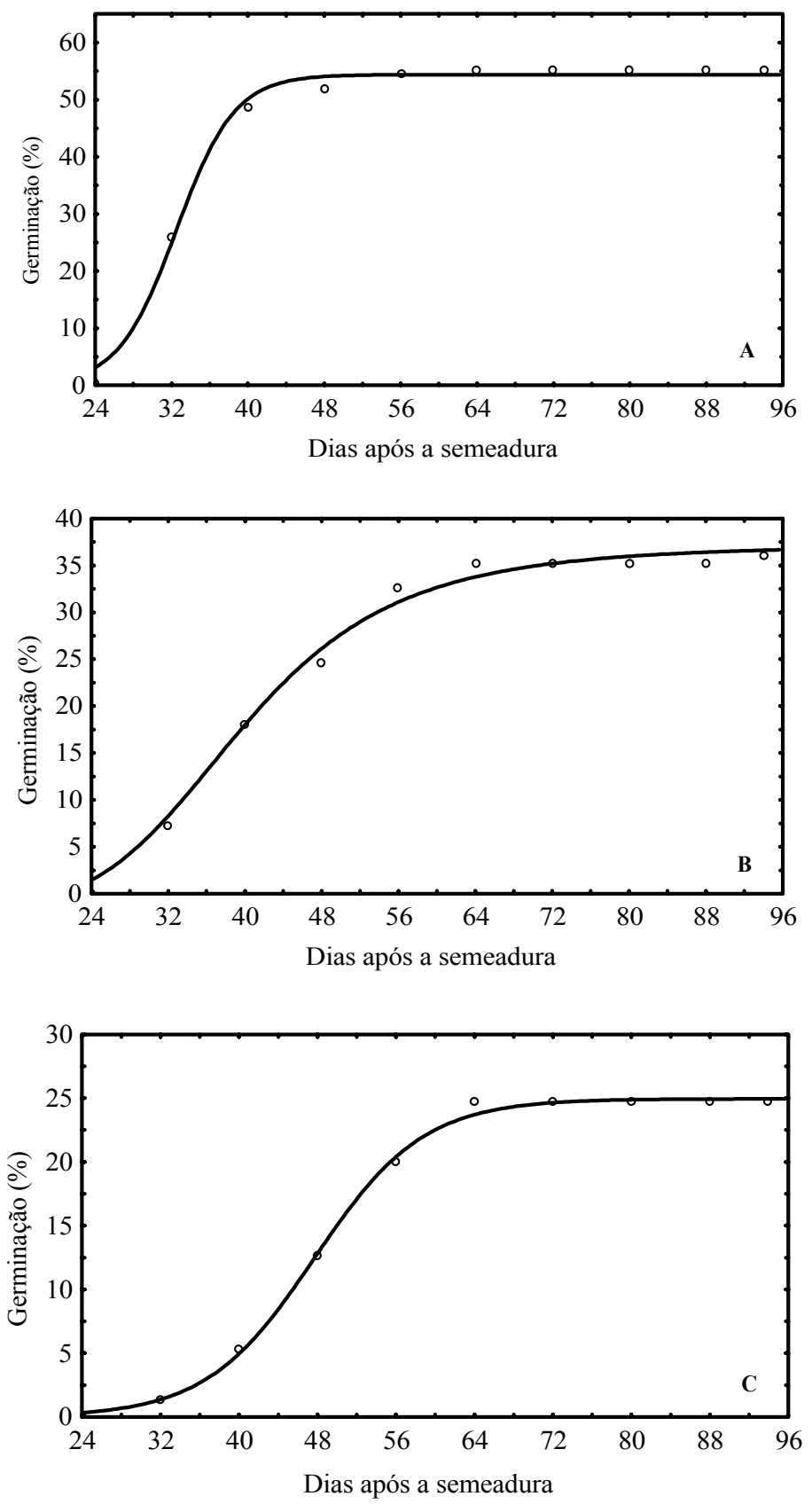

Figura 4 - A: Germinação de sementes de Micropholis cf. venulosa, em função do tempo, com grau de umidade de $42,6 \%$, cuja equação foi $y=54,39 / 1+43930,75(\exp (-0,33 x)), r^{2}=0,98 ; B$ : grau umidade de $32,5 \%$, cuja equação foi $y=1,46(82266390)+37,17 \mathrm{x}^{4,94} / 82266390+\mathrm{x}^{4,94}, \mathrm{r}^{2}=0,98$; C: grau umidade de $28,9 \%$, cuja equação foi $y=24,95 / 1+5597,78(\exp (-0,18 x)), r^{2}=0,98$. 
Tabela 1 - Dias para início da germinação, tempo médio de germinação, e percentagens de plântulas anormais e de sementes mortas em curupixá (Micropholis cf. venulosa).

\begin{tabular}{lccccc}
\hline Tratamentos & Umidade & $\begin{array}{c}\text { Dias para } \\
\text { iniciar a } \\
\text { germinação }\end{array}$ & $\begin{array}{c}\text { Tempo } \\
\text { médio de } \\
\text { germinação }\end{array}$ & $\begin{array}{c}\text { Plântulas } \\
\text { anormais }\end{array}$ & $\begin{array}{c}\text { Sementes } \\
\text { mortas }\end{array}$ \\
\hline Sementes frescas & 42,6 & $25,5 \mathrm{~b}$ & $33,2 \mathrm{~b}$ & $4,5 \mathrm{a}$ & $40,5 \mathrm{c}$ \\
Sementes secas por 72 hs. & 32,5 & $27,7 \mathrm{ab}$ & $41,4 \mathrm{ab}$ & $6,0 \mathrm{a}$ & $58,0 \mathrm{~b}$ \\
Sementes secas por 96 hs. & 28,9 & $35,7 \mathrm{a}$ & $45,5 \mathrm{a}$ & $5,3 \mathrm{a}$ & $70,0 \mathrm{a}$ \\
\hline
\end{tabular}

Médias seguidas da mesma letra, na coluna, não diferem estatisticamente pelo teste de Tukey $(P>0,05)$

\section{CONCLUSÕES}

Frutos e sementes de curupixá apresentam ampla variabilidade nas suas características biométricas;

As sementes, semeadas imediatamente após a dispersão, apresentam germinação baixa e acentuada desuniformidade no processo de germinação;

As sementes apresentaram sensibilidade ao dessecamento, enquadrando-se no grupo das recalcitrantes.

\section{BIBLIOGRAFIA CITADA}

Aimex - Associação das Indústrias Exportadoras de Madeiras do Estado do Pará. 1998. Estatísticas das exportações dos produtos serrados e manufaturados de madeira. Belém. $7 \mathrm{p}$.

Baskin, C.C.; Baskin, J.M. 1998. Seeds: ecology, biogeography, and evolution of dormancy and germination. Academic Press, London. 666 p.

Beiguelman, B. 1991. Curso prático de bioestatística. 2 ed., Sociedade Brasileira de Genética, Ribeirão Preto. 231p.

Brasil. 1992. Regras para análise de sementes. Ministério da Agricultura e Reforma Agrária, Brasília. 365p.

Caballero, W. 1985. Introdución a la estadística. 1 ed., IICA, Costa Rica. 289p.

Carvalho, J.E.U.; Müller, C.H. 1998. Níveis de tolerância e letal de umidade em sementes de pupunheira, Bactris gasepaes. Revista Brasileira de Fruticultura, 20(3): 283-289.

Carvalho, J.E.U.; Nascimento, W.M.O. do. 2000. Sensibilidade de sementes de jenipapo (Genipa americana L.) ao dessecamento e ao congelamento. Revista Brasileira de Fruticultura, 22(1): 53-56.

Carvalho, J.E.U.; Nascimento, W.M.O.; Müller, C.H. 1998. Características físicas e de germinação de sementes de espécies frutiferas nativas da Amazônia. EMBRAPA-CPATU, Boletim de Pesquisa, 203. Belém. 18p.

Cruz, E.D.; Carvalho, J.E.U.; Leão, N.V.M. 2001a. Métodos para superação da dormência e biometria de frutos e sementes de Parkia nitida Miquel. (Leguminosae Mimosoideae). Acta Amazonica, 31(2): 167-177.

Cruz, E.D.; Martins, F. de O.; Carvalho, J.E.U. 2001b. Biometria de frutos e sementes de jatobá-curuba (Hymenaea intermedia Ducke, Leguminosae - Caesalpinioideae). Revista Brasileira de Botânica, 24(2): 161-165.

Chin, H.F. 1988. Recalcitrant seeds: a status report. International Board for Genetic Resources, Rome. $28 \mathrm{p}$.

Corbineau, F.; Côme, D. 1988. Storage of recalcitrant seeds of four tropical species. Seed Science and Technology, 16(1): 97-103.

Cunha, R. Eira, M.T.S.; Rita, I. 1995. Germination and desiccation studies on wild nutmeg seed (Virola surinamensis). Seed Science and Technology, 23(1): 43-49.

Dayal, B.R.; Kaveriappa, K.M. 2000. Effect of Dessication and temperature on germination and vjgour of the seeds of Hopea parviflora Beddone and $H$. ponga (Dennst) Mabb. Seed Science and Technology. 28(2): 497-506. 
Duke, J.A.; Polhill, R.M. 1981. Seedlings of leguminosae. In: Polhill, R.M.; Raven, P.H. (ed). Advances in legume systematics v.2 Royal Botanic Garden, Richmond, p.941-949.

Edmond, J.B.; Drapala, W.J. 1965. The effects of temperature, sand and soil, and acetone on germination of okra seed. Proceedings of the American Society for Horticultural Science. 71: 428-434.

Edwards, D.G.W. 2000. Forest tree seeds at the end of the $20^{\text {th }}$ century: major accomplishments and needs. In: Krishnapillay, B.; Soepadmo, E.; Arshad, N.L.; Wong, A.; Appanah, S.; Chik, S.W.; Manokaran, N.; Tong, H.L.; Choon, K.K. (Eds.). International Union of Forestry Research Organization, IUFRO, Kuala Lumpur, Malaysia, IUFRO WORLD CONGRESS, 21, v.1, p.54.

Knowles, O.H.; Parrotta, J.A. 1995. Amazonian forest restoration: an innovative system for native species selection based on phenological data and field performance indices. Commonwealth Forestry Review. 74(3): 230-243.

Neves, C.S.V.J. 1994. Sementes recalcitrantes: revisão de literatura. Pesquisa Agropecuária Brasileira, 29(9): 1.459-1.467.

Roosmalen, M.G. van; Garcia, O.M. da C.G. 2000. Fruit of Amazonian forest. Part II: Sapotaceae. Acta Amazonica. 39(2):187-290.
Souza, M.H.; Magliano, M.M.; Camargos, J.A.A. 1997. Madeiras tropicais brasileiras. Instituto Brasileiro do Meio Ambiente e dos Recursos Naturais Renováveis - Laboratório de Produtos Florestais, Brasília. 151p.

Spjut, R.W. 1994. A Systematic treatment of fruit types. Memoirs of the New York Botanical Garden, 70: 1-82

Statsoft. 1998. Statistica for Windows. General conventions and statistica. Stasoft, Tulsa, OK. Inc.

Tompset, P.B. 1985. The influence of moisture content and storage temperature on the viability of Shorea almon, Shorea robusta and Shorea roxburghii seed. Canadian Journal Forest Research. 15: 1074-1079.

Varghese, B.; Naithani, S.C. 2000. Desiccation induced loss of vigour and viability during storage in neem (Azadirachta indica A. Juss) seeds. Seed Science and Technology, 28(2): 485-496.

Vázquez-Yanes, C.; Aréchiga, M.R. 1996. Ex situ conservation of tropical rain forest seed: problems and perspectives. Interciencia. 21(5): 293-298.

Villachica, H.; Carvalho, J.E.U. de; Müller, C.H.; Díaz, C.; Almanza, M. 1996. Frutales y hortalizas promisorios de la Amazonia. Tratato de Cooperación Amazonica, Secretaria Pro-Tempore. Lima. $367 \mathrm{p}$.

Zar, J.H. 1996. Biostatistical analysis. 3 ed. New Jersey: Prentice Hall, 988p. 